\title{
Twin reversed arterial perfusion syndrome in a monochorionic monoamniotic twin pregnancy
}

\author{
Hacer Yapıcıoğlu-Yıldızdaş¹, Ümit Ece², Mete Sucu ${ }^{3}$, Gülseren Yurdakul², Hüseyin \\ Şimşek ${ }^{1}$, Ferda Özlü ${ }^{1}$ \\ Division of ${ }^{1}$ Neonatology, Department of Pediatrics, ${ }^{3}$ Division of Perinatology, Department of Obstetrics and Gynecology, \\ Çukurova University, Faculty of Medicine, ${ }^{2}$ Department of Pediatrics, Private Adana Algomed Hospital, Adana, Turkey. \\ E-mail: hyapicioglu@cu.edu.tr \\ Received: 27th March 2017, Accepted: 1st May 2017
}

SUMMARY: Yapıcıŏ̆lu-Yıldızdaş H, Ece Ü, Sucu M, Yurdakul G, Şimşek $\mathrm{H}$, Özlü $\mathrm{F}$. Twin reversed arterial perfusion syndrome in a monochorionic monoamniotic twin pregnancy. Turk J Pediatr 2017; 59: 724-727.

Twin reversed arterial perfusion syndrome is mostly seen in monochorionic diamniotic twin pregnancies with an estimated incidence of 1/9500-11000 pregnancies. One of the twins is acardiac with various abnormalities especially with upper part of the body, and mortality is $100 \%$. The other twin functions as a pump twin and mostly has polyhydramnios and heart failure; and mortality rate is high due to prematurity and heart failure. Herein we report a TRAP syndrome and the prognosis of pump twin who was born at 30 weeks gestational age.

Key words: twin reversed arterial perfusion syndrome, newborn.

Twin-twin transfusion and twin reversed arterial perfusion (TRAP) syndromes are mostly seen in monochorionic diamniotic (MCDA) twin pregnancies. A 2015 study estimated the incidence as $2.6 \%$ of monochorionic twin

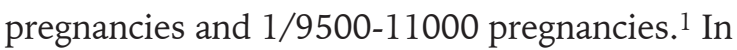
TRAP syndrome, there is mostly arterioarterial anastomosis in the placenta ${ }^{2}$ and one of the twins is acardiac and gets his blood from the other pump twin. Pump twin has normal pattern of fetal circulation, however a portion of its cardiac output is reversed to the acardiac twin through the arterio-arterial anastomosis. This abnormal pattern causes less oxygenated blood in the lower part of the body and poor perfusion of the upper body and head. The acardiac twin mostly does not have upper part of the body and the pump twin mostly has heart failure. ${ }^{3}$ Mortality is $100 \%$ in the acardiac twin and almost 50\% in the pump twin due to heart failure and prematurity. ${ }^{4}$

Herein we report a premature baby boy with TRAP syndrome with acardiac acephalus twin and his prognosis in Newborn Intensive Care Unit.

\section{Case Report}

At 25 weeks of gestation, a 35-year-old G5P2 female was referred to our Obstetrics and Perinatology Department for exitus of one of the twins. However, ultrasonographic findings showed monochorionic monoamniotic twin gestation with one normal and one acardiac twin with only one leg, polyhydramnios and reversed blood flow (Fig. 1). The estimated weight of acardiac and normal twin was $640 \mathrm{~g}$ and $1039 \mathrm{~g}$, respectively. Size of the acardiac twin to that of the normal twin was less than 0.7 indicating better prognosis. The normal twin did not have the signs of highoutput cardiac failure: cardiomegaly, pericardial and pleural effusion, ascites, and tricuspid regurgitation. Parents were informed about the TRAP syndrome and mother was monitored regularly weekly. In 30th week of gestation, she was admitted to hospital for vaginal bleeding. The donor fetus was normal except for minimal pericardial fluid collection. Ultrasonography showed polyhydramnios, fetal echocardiography showed biventricular hypertrophy of the heart. Amnioreduction was performed, $680 \mathrm{ml}$ amnion fluid was drained. Magnesium infusion and 
betamethasone were started and 2 days later, lower section caesarean section was carried out. The donor twin was boy, $1840 \mathrm{~g}$ (90 p). Apgar scores were 5 and 7 in the 1 st and 5 th minutes. He was intubated and surfactant was administered. The recipient acardiac twin was $1700 \mathrm{~g}$, Apgar score was 0. The donor twin had bilateral cataracts, abdominal ascites, $2 \mathrm{~cm}$ hepatosplenomegaly, edema and cardiomegaly WBC $7,400 / \mathrm{mm}^{3}$, hemoglobin $20,1 \mathrm{~g} / \mathrm{dl}$, platelet: $200,000 / \mathrm{mm}^{3}$, CRP $0.04 \mathrm{mg} / \mathrm{dl}$ and biochemistry tests were in normal limits except for $1.38 \mathrm{~g} / \mathrm{dl}$ of albumin and $2.62 \mathrm{~g} / \mathrm{dl}$ of protein. Dopamine and ampicillin/gentamycin were started, albumin was infused. Blood culture revealed Acinobacter baumanni on the 6th day of life and antibiotics were changed to meropenem. He was intubated for 47 days and he had orogastric drainage until 22th day of life. Although there was no other bacteria growth in the cultures, he had trombocytopenia and feeding intolerance for a long time, he was parenterally fed. He had cholestasis; A,D,E and $\mathrm{K}$ vitamins and ursodeoxicolic acid were started. He was discharged on the 65th day of life. Left and right lensectomy, anterior vitrectomy and posterior capsulotomy were performed when he was 96 days old and 126 days old respectively. He is still followed in the outpatient clinic. He is 7 months old (corrected 5.5 months old), $6500 \mathrm{~g}$ (10-25 p), head circumference $38 \mathrm{~cm}(<5 \mathrm{p})$ and length $60.5 \mathrm{~cm}$ (5 p). He has had head control only for one month, he is responding and smiling to his mother's voice. Informed consent of the parents was obtained.

\section{Discussion}

Twin reversed arterial perfusion is a rare syndrome. Although its prevalence was estimated to be $1 / 35000$ before $1953^{5}$, it is increasingly being diagnosed in the first trimester as a consequence of widespread scan for nuchal translucency measurement. Acardiac acephalus, acardius acormus, acardius amorphus and acardius myelacephalus types are reported. The most common anomaly is acardiac acephalus, in which the heart and head are absent, like the present case. ${ }^{6}$

Prenatal diagnosis is based on the characteristic ultrasound findings such as one normal and one acardiac fetus, lack of one vessel and

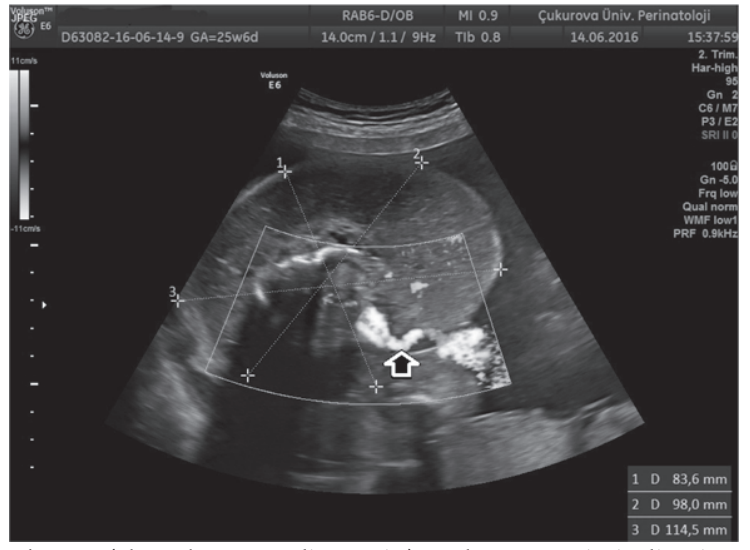

Fig. 1. (shapeless acardiac twin) : The arrow is indicating reversed umbilical blood flow in the umblical artery of the acardiac fetus. Acardiac twin is sharing the same amniotic cavity with the normal fetus. As seen in the sonography amniotic fluid is increased.

reversed umbilical blood flow in the umbilical artery of the acardiac fetus and high-output heart failure, polyhydramnious, hydrops and ascites in the pump fetus. ${ }^{7}$ In the present case we also noted polyhydramnios, hydrops and ascites. Monochorionic twins should be examined carefully for TRAP syndrome in the first trimester. Unfortunately, in our case, TRAP syndrome was not diagnosed until mother was referred to our hospital. TRAP syndrome should be suspected if one of the twins appear as an amorphous mass and has no heartbeat.

Organogenesis defect due to anastomosis in the placenta in the early period of gestation is suggested in pathogenesis. ${ }^{8}$ Blood circulation between twins are provided either via arteryartery and vein-vein anastomosis on the placental surface. ${ }^{9}$ Monoamniotic twins are rare and is 1 in 20 monochorionic twin pregnancies. Anastomosis are nearly all arterioarterial in monoamniotic twins. In TRAP syndrome, there is imbalance of interfetal circulation which causes less oxygen saturated blood flow to the upper part of the body leading to maldevelopment of head, neck and upper extremities. To our knowledge, there is no literature dealing with the genetic study of acardiac fetusus. However, Klinefelter syndrome and Prune Belly sequence have been reported in co-twin of acardiac fetuses. ${ }^{10,11}$

The optimal management of TRAP syndrome is controversial ranging from conservative management to elective termination or surgical intervention such as occlusion of umbilical cord 
of acardiac fetus with laser coagulation, bipolar cord coagulation and radiofrequency ablation (RFA) and rarely fetoscopic cord ligation. ${ }^{12-15}$ Treatment is focused on improving the outcome of pump fetus. Unfortunately, survival rate in donor fetus is also low. Moore et al. ${ }^{3}$ suggested that if the actual acardiac pump twin weight ratio is greater than 0.7 , the incidence of preterm delivery, polyhydramnios and heart failure is $90 \%, 40 \%$ and $30 \%$, respectively. Lewi et al. ${ }^{16}$ reported the prognosis of 26 TRAP syndromes diagnosed in the first trimester with a mean gestational age of 12 weeks. Two of the pregnancies were terminated, one on parental request and one after diagnosis of brain malformation. By 16-18 weeks, 8 pump $(33 \%)$ fetus died and there was spontaneous cessation of flow to the acardiac fetus in 5 $(21 \%)$ of the pregnancies. Of the remaining $11(46 \%)$ cases, 1 pregnancy was terminated for megacystis. In the other 10 cases, intrafetal coagulations ( 6 laser and 1 RFA) and 3 cord laser coagulations were performed. 1 of them was a miscarriage after membrane rupture at 19 weeks and 9 of them were born healthy at a median gestation of 37 (28-40) weeks. In the spontaneous regression of reverse perfusion, 2 were born healthy. So, the overall survival rate of the pump twin was $46 \%(11 / 24)$ in TRAP syndrome cases diagnosed in the first trimester. Cabassa et al. ${ }^{17}$ reported the use of RFA in 7 TRAP syndrome cases at a median age of 17 weeks and reviewed the literature. The success of RFA was $71 \%(5 / 7)$ and $85 \%(75 / 85)$ in the 6 studies. Intrafetal ablation between 1426 weeks has also similar success in neonatal survival $(82 \%) .{ }^{18}$ Unfortunately, the present patient was 25 weeks on first admission, and we preferred to observe the pregnancy conservatively. In conservative management, weekly ultrasound is suggested to look for hydrops fetalis for the pump fetus. We observed our case for 5 weeks and amnioreduction was performed, he had hydrops, respiratory distress and bilateral cataracts when he was born. To our knowledge, cataract was not reported in donor fetus before.

In conclusion twin reversed arterial perfusion syndrome is a rare syndrome and should be suspected in monochorionic twins if one of the twin is acardiac. Parents should be informed about the survival of the donor and acardiac fetuses and treatment modalities.

\section{REFERENCES}

1. Van Gemert MJ, van den Wijngaard JP, Vandenbussche FP. Twin reversed arterial perfusion squence is more common than generally accepted. Birth Defects Res A Clin Mol Teratol 2015; 103: 641-643.

2. Schwarzler P, Ville Y, Moscosco G, Tennstedt C, Bollmann R, Chaoui R. Diagnosis of twin reversed arterial perfusion sequence in the first trimester by transvaginal color Doppler ultrasound. Ultrasound Obstet Gynecol 1999; 13: 143-146.

3. Moore TR, Gale S, Benirschke K. Perinatal outcome of forty-nine pregnancies complicated by acardiac twinning. Am J Obstet Gynecol 1990; 163: 907-912.

4. Van Allen MI, Smith DW, Shepard TH. twin reversed arterial perfusion (TRAP) sequence: a study of 14 twin pregnancies with acardius. Semin Perinatol 1983; 7: 285-293.

5. Gillim DL, Hendricks CH. Holoacardius; review of the literature and case report. Obstet Gynecol 1953; 2: 647-653.

6. Aggarwal N, Suri V, Saxena S, Malhotra S, Vasishta K, Saxena AK. Acardiac acephalus twins: a case report and review of the literature. Acta Obstet Gynecol Scand 2002; 81: 983-984.

7. Mastrobattista JM, Lucas MJ. Diagnosis and management of twin reversed arterial perfusion (TRAP) sequence. https://www.uptodate.com/contents/diagnosis-andmanagement-of-twin-reversed-arterial-perfusion-trapsequence.

8. Hecher K, Ville Y, Nicolaides KH. Color Doppler ultrasonography in the identification of communicating vessels in twin-twin transfusion syndrome and acardiac twins. J Ultrasound Med 1995; 14: 37-40.

9. Wong AE, Sepulveda W. Acardiac anomaly: current issues in prenatal assessment and treatment. Prenat Diagn 2005; 25: 796-806.

10. Rehder H, Schoner K, Kluge B, Louwen F, Schwinger E, Neesen J. Klinefelter twins presenting with discordant aneuploidies, acardia, forked umbilical cord and with different gonadal sex despite monozygosity. Prenat Diagn 2012; 32: 173-179.

11. Buntinx IM, Bourgeois N, Buytaert PM, Dumon JE. Acardiac amophous twin with prune belly squence in the co-twin. Am J Med Genet 1991; 39: 453-457.

12. Ville Y, Hyett JA, Vandenbussche FP, Nicolaides KH Endoscopic laser coagulation of umbilical cord vessels in twin reversed arterial perfusion sequence. Ultrasound Obstet Gynecol 1994; 4: 396-398.

13. King JR, Conturie CL, Ouzounian JG, Korst LM, Llanes A, Chmait RH. Umbilical cord occlusion via laser coagulation in monochorionic multifetal gestations before and after 20 weeks of gestation. Fetal Diagn Ther 2017; 42: 9-16.

14. Lee H, Wagner AJ, Sy E, et al. Efficacy of radiofrequency ablation for twin-reversed arterial perfusion sequence. Am J Obstet Gynecol 2007; 196: 459-e1-4.

15. Deprest JA, Audibert F, Van Schoubroeck D, Hecher K, Mahieu-Caputo D. Bipolar coagulation of the umbilical cord in complicated monochorionic twin pregnancy. Am J Obstet Gynecol 2000; 182: 340-345. 
16. Lewi L, Valencia C, Gonzalez E, Deprest J, Nicolaides $\mathrm{KH}$. The outcome of twin reversed arterial perfusion sequence diagnosed in the first trimester. Am J Obstet Gynecol 2010; 203: 213.e1-4.

17. Cabassa P, Fichera A, Prefumo F et al.The use of radiofrequency in the treatment of twin reversed arterial perfusion sequence: a case series and review of the literature. Eur J Obstet Gynecol Reprod Biol 2013; 166: 127-132.
18. Pagani G, D'Antonio F, Khalil A, Papageorghiou A Bhide A, Thilaganathan B. Intrafetal laser treatment for twin reversed arterial perfusion sequence: cohort study and meta-analysis. Ultrasound Obstet Gynecol 2013; 42: 6-14. 